\title{
Light Absorption and Scattering by Silver/Silver Sulfide Hybrid Nanoparticles
}

Tatiana A. Estrada-Mendoza $\ddagger$, Daniel Willett $\ddagger \dagger$, and George Chumanov $*$

‡Department of Chemistry, Clemson University, Clemson, South Carolina 29634, United States

\section{Suplemental information}

Zoom out TEM and AFM raw images for AgNPs, mid point reaction and end point

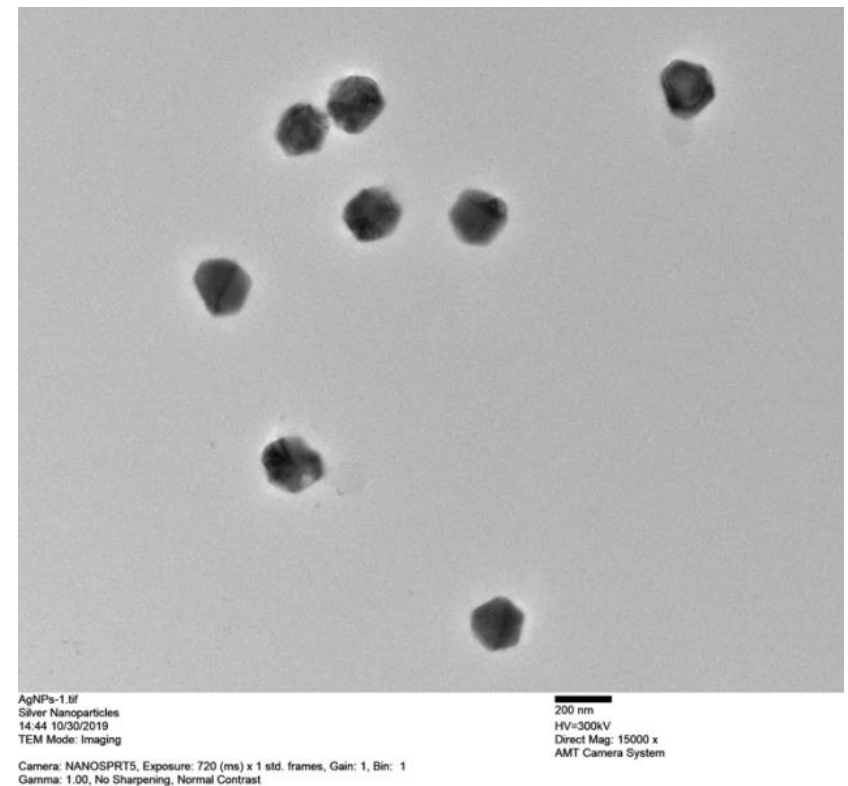

Figure S 1: TEM Image $15 \mathrm{kx}$ of $\lambda 497 \mathrm{AgNPs}$ obtained before sulfidation reaction 


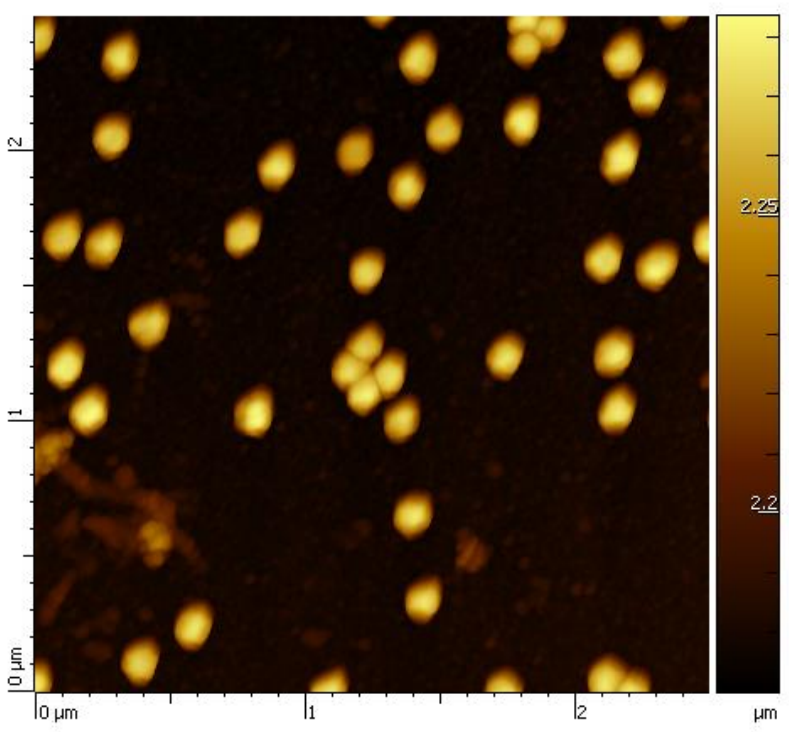

Figure S 2: AFM image $2.5 \mu \mathrm{m}$ scanning area of $\lambda 497$ Ag NPs area obtained before sulfidation reaction

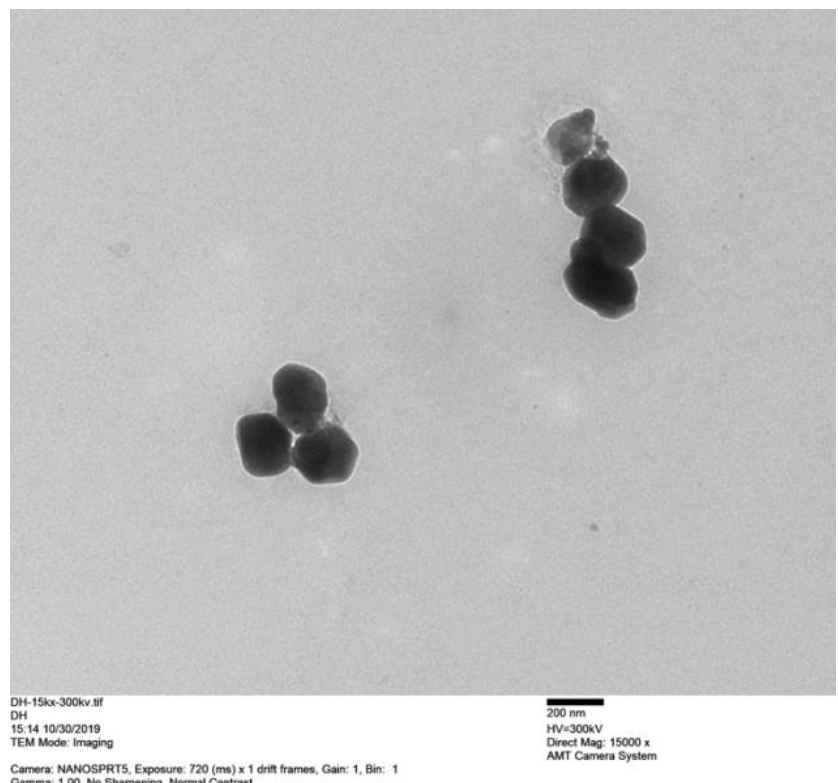

Figure S 3: TEM image $15 \mathrm{kx}$ of $\lambda 497 \mathrm{Ag} / \mathrm{Ag}_{2} \mathrm{~S}$ hybrid NPs obtained at midpoint of the reaction 


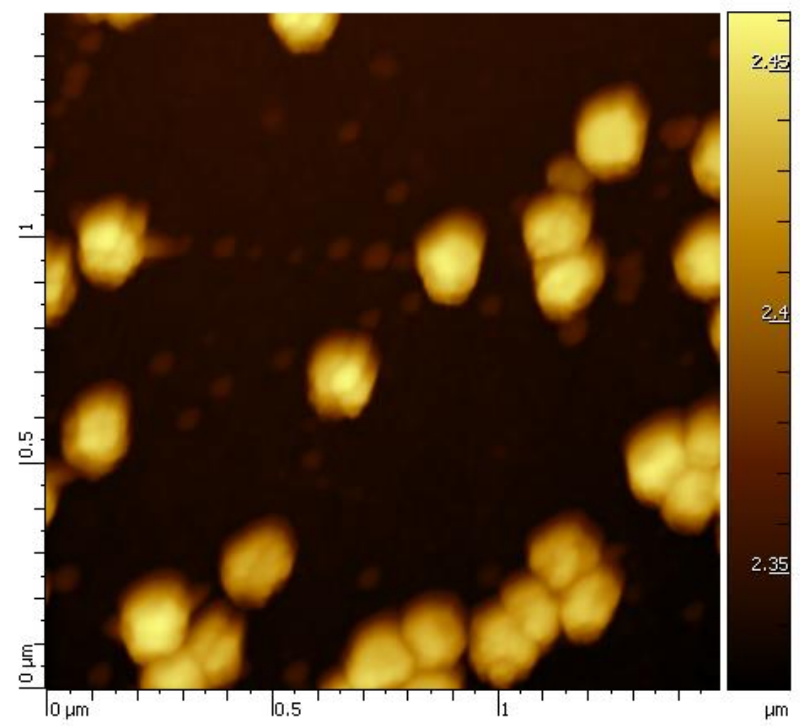

Figure S 4: AFM image $1.5 \mu \mathrm{m}$ scanning area of $\lambda 497 \mathrm{Ag} / \mathrm{Ag}_{2} \mathrm{~S}$ hybrid NPs obtained at the midpoint of the reaction obtained at mid-point of the reaction

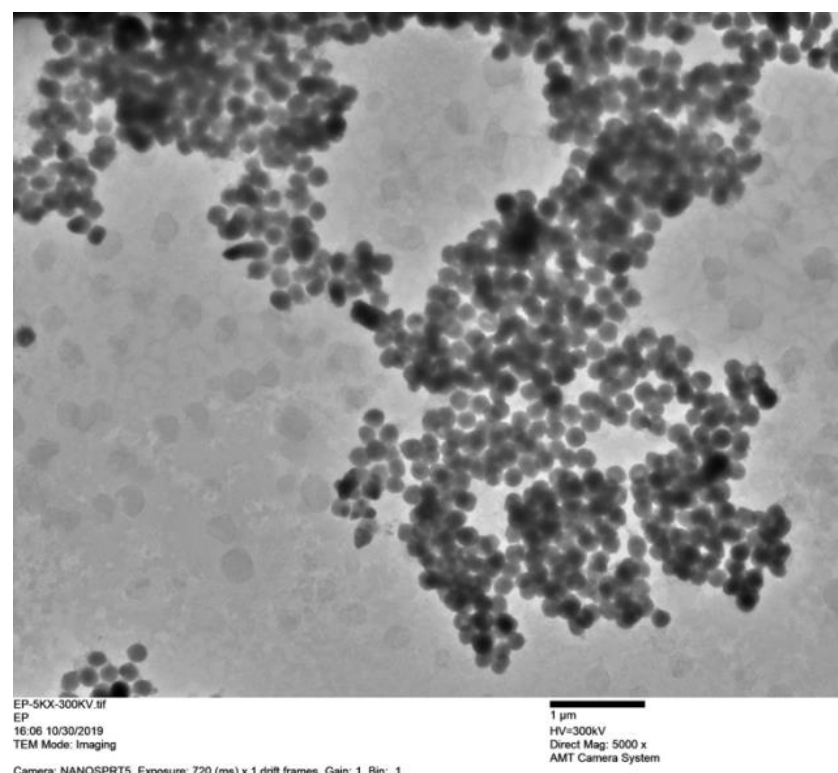

Figure S 5: TEM image $5 \mathrm{kx}$ of $\lambda 497 \mathrm{Ag}_{2} \mathrm{~S}$ NCs obtained at end point of the reaction 


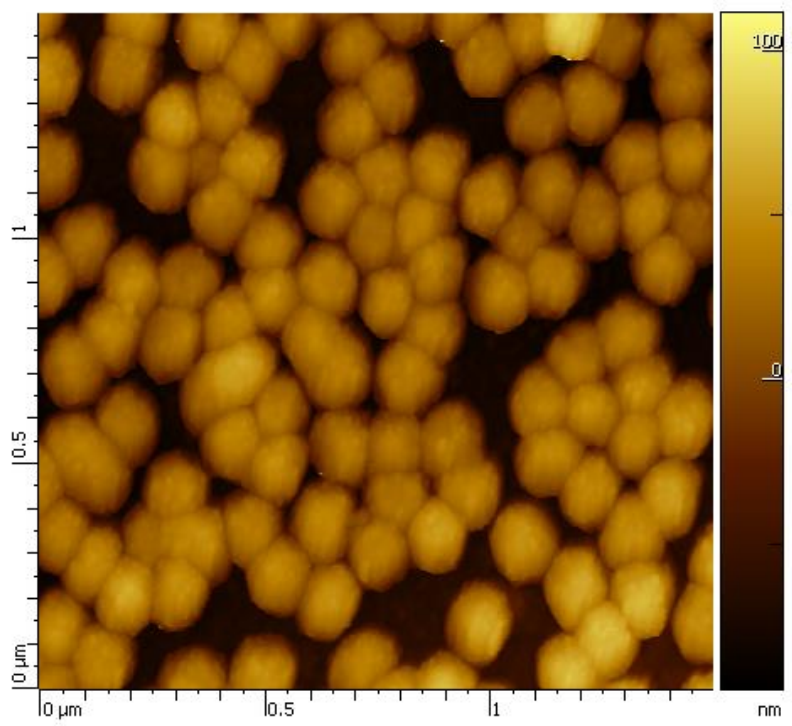

Figure S 4: AFM image $1.5 \mu \mathrm{m}$ scanning area of $\lambda 497 \mathrm{Ag}_{2} \mathrm{~S}$ NCs obtained at end point of the reaction

Figures for the sulfidation of AgNPs of two different sizes different sizes.

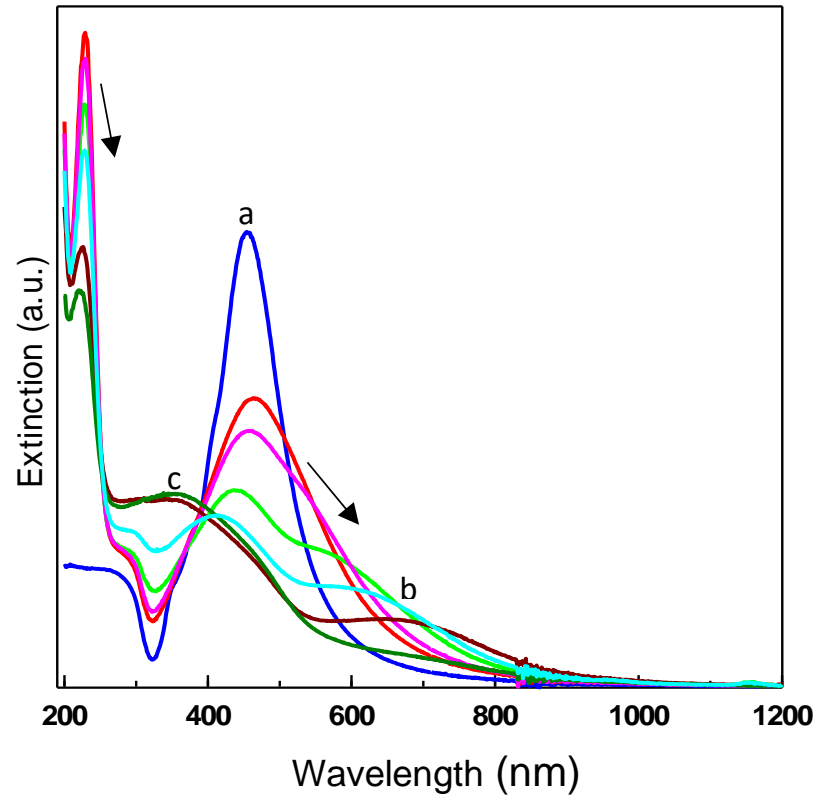

Figure S 7: The extinction spectra of $\lambda 455 \mathrm{Ag} / \mathrm{Ag}_{2} \mathrm{~S}$ hybrid NPs formed at different stages of the sulfidation reaction. The arrows indicate the direction of the spectra evolution as the sulfidation reaction proceeds in time. (a) before sulfidation, (b) mid-point of reaction, (c) end point of reaction 


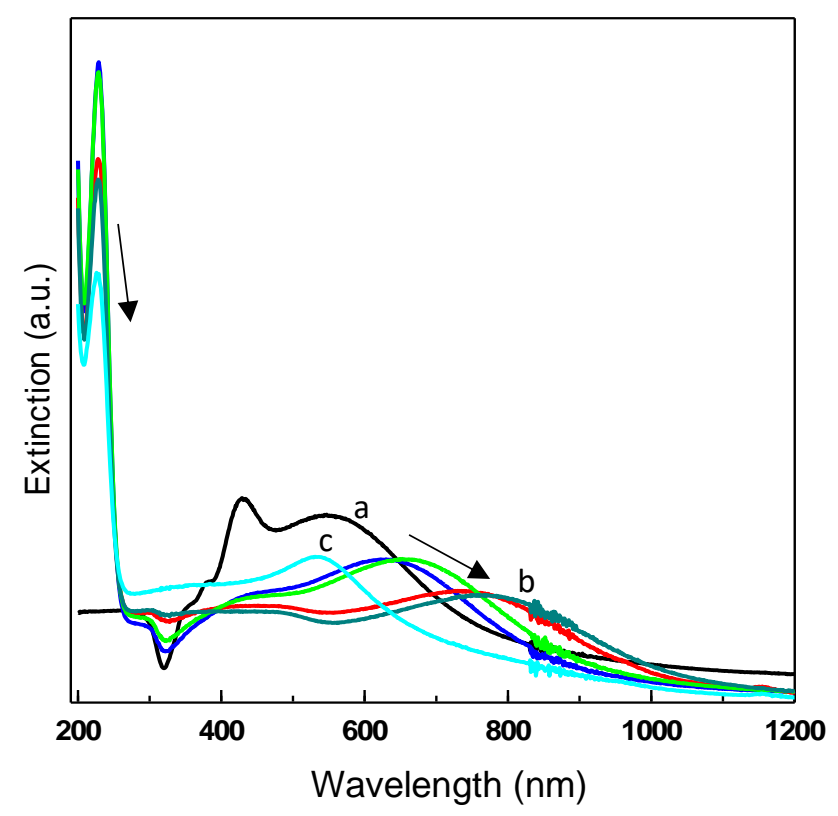

Figure S 8: The extinction spectra of $\lambda 540$

$\mathrm{Ag} / \mathrm{Ag}_{2} \mathrm{~S}$ hybrid NPs formed at different stages of the sulfidation reaction. The arrows indicate the direction of the spectra evolution as the sulfidation reaction proceeds in time. (a) before sulfidation, (b) mid-point of reaction, (c) end point of reaction

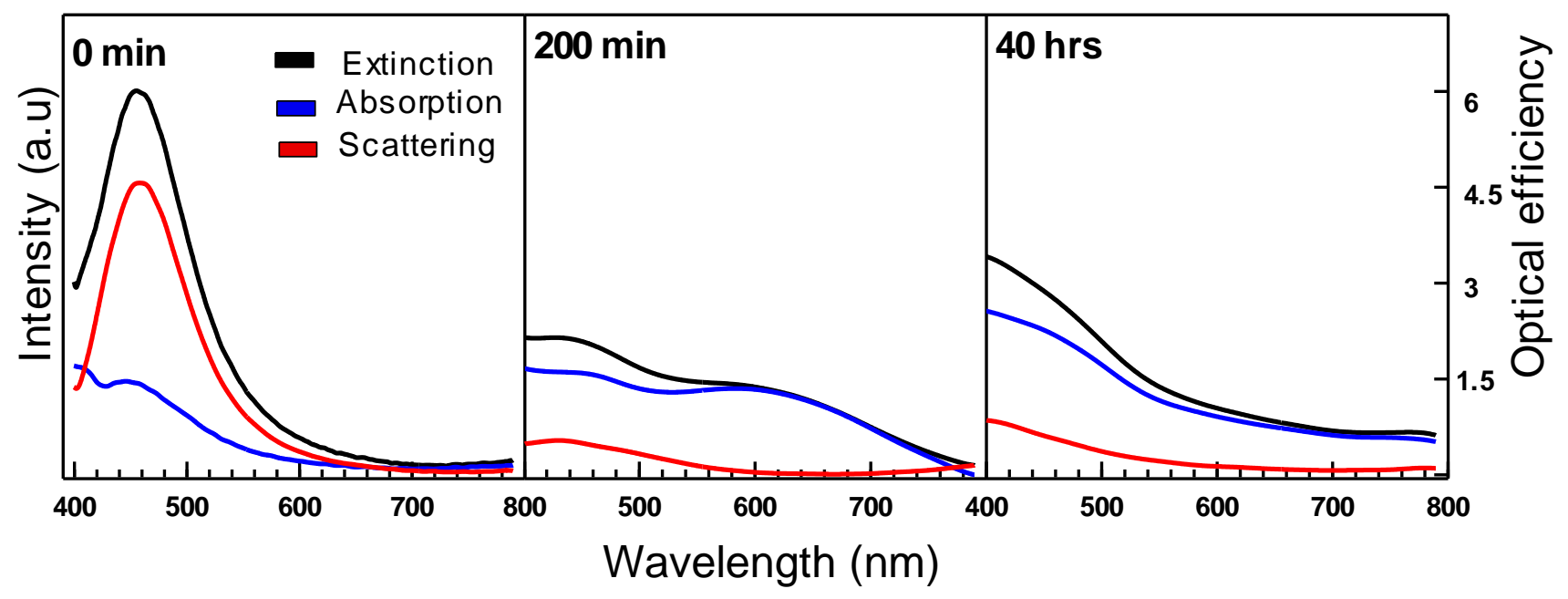

Figure S 9: Extinction, absorption and scattering spectrum of sulfidized AgNP of resonance $\lambda 455 \mathrm{~nm}$. Study performed over a 40-hour period. 


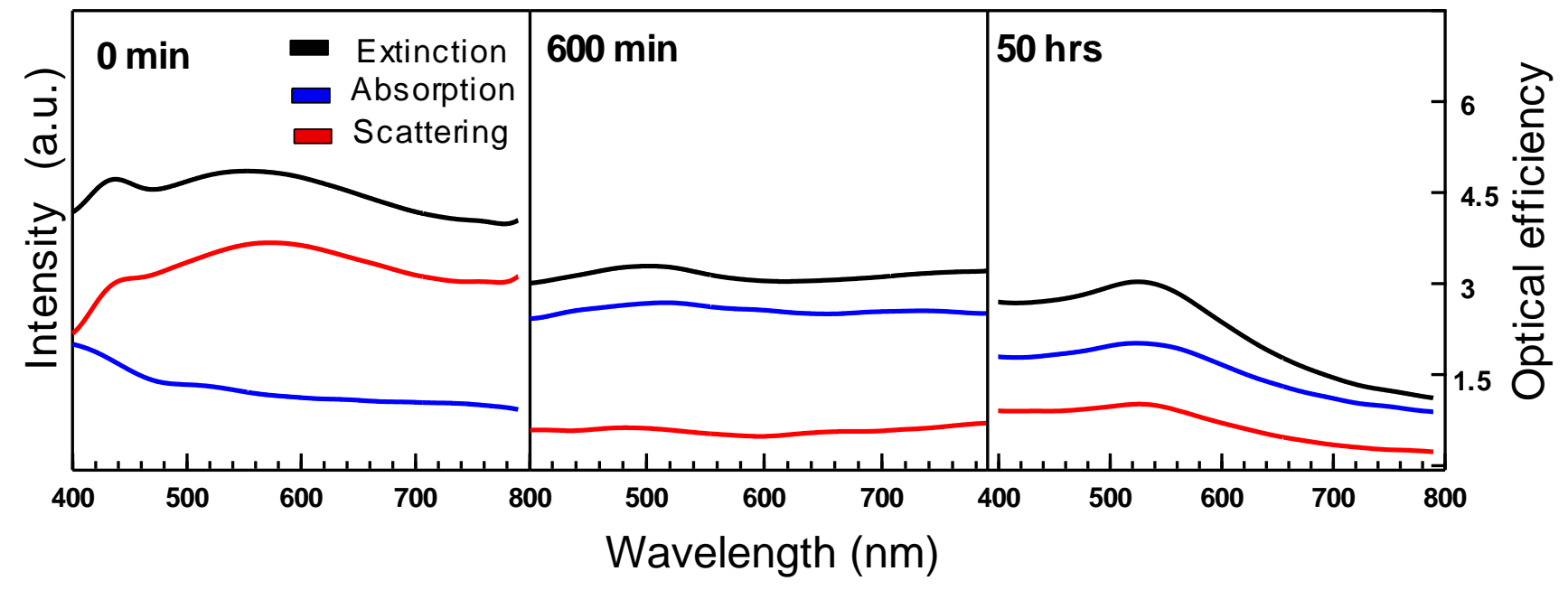

Figure S. 10: Extinction, absorption and scattering spectrum of sulfidized AgNP of resonance $\lambda 540 \mathrm{~nm}$. Study performed over a 50-hour period.

EDS data of $\lambda 497, \lambda 455, \lambda 540$ NPs at different points of sulfidation reaction
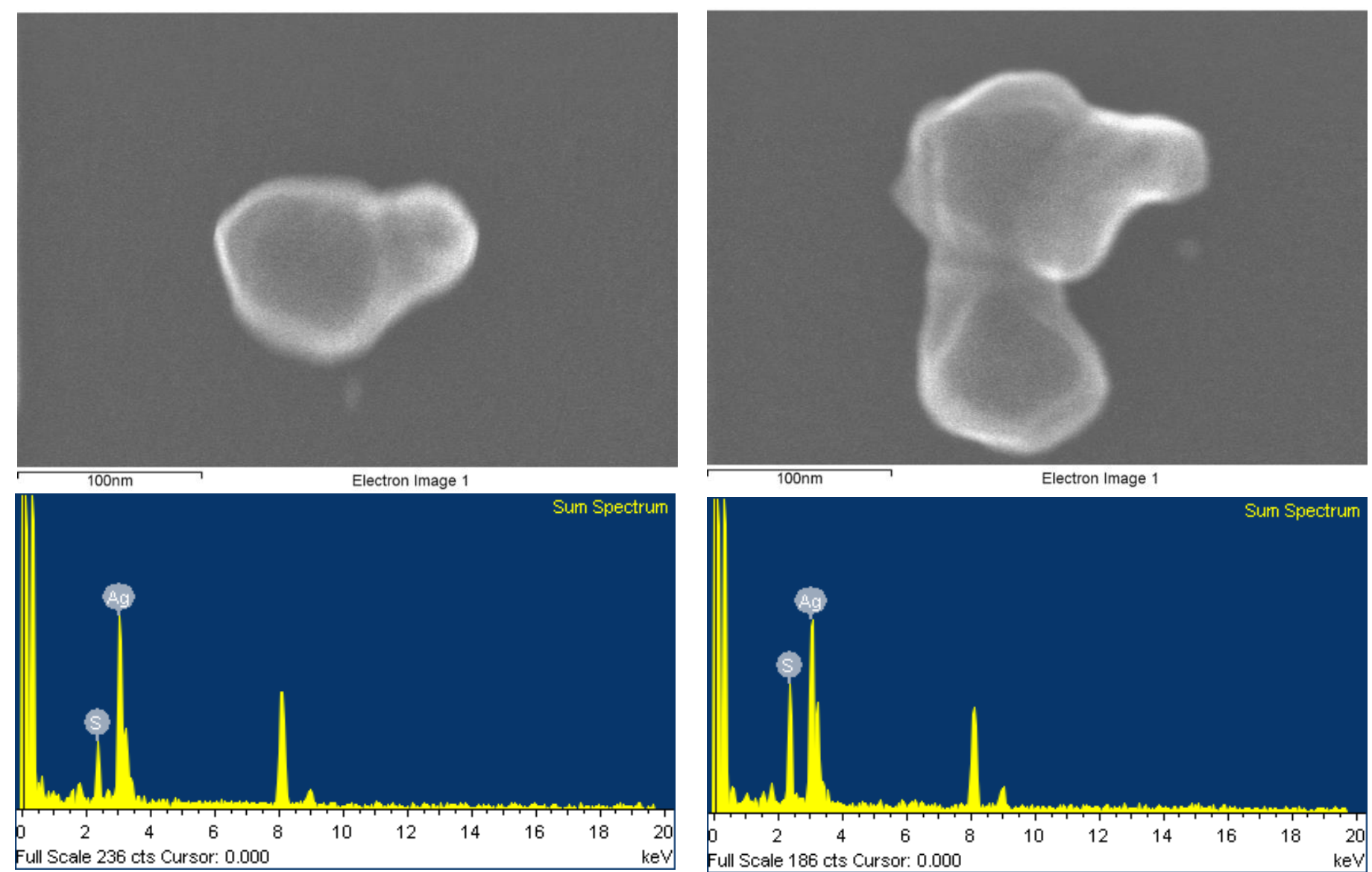

Figure S 11: EDS images and data of end point of sulfidation reaction of $\lambda 497$ particles 

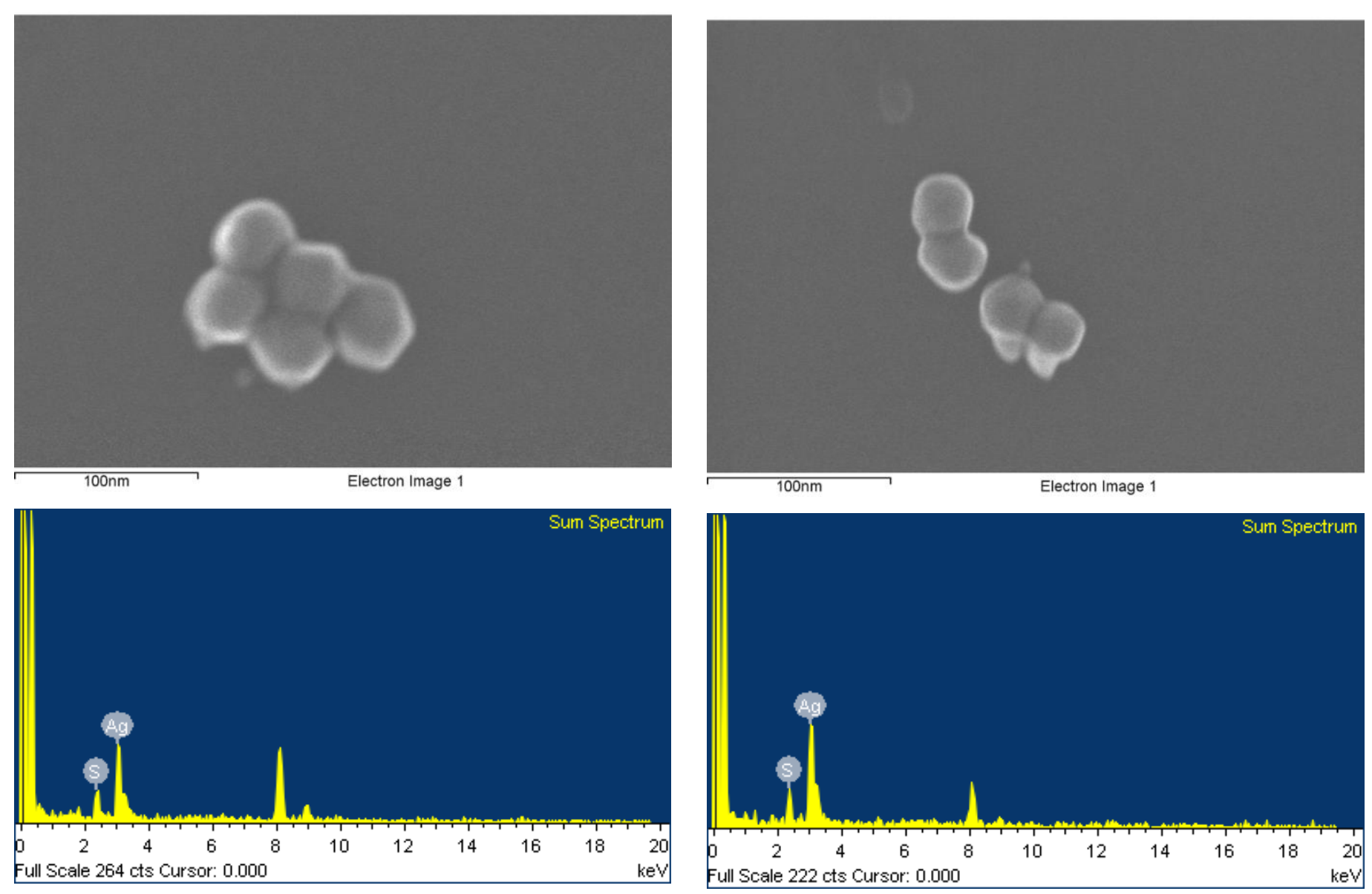

Figure S 12: EDS images and data of mid-point of sulfidation reaction of $\lambda 455$ particles 

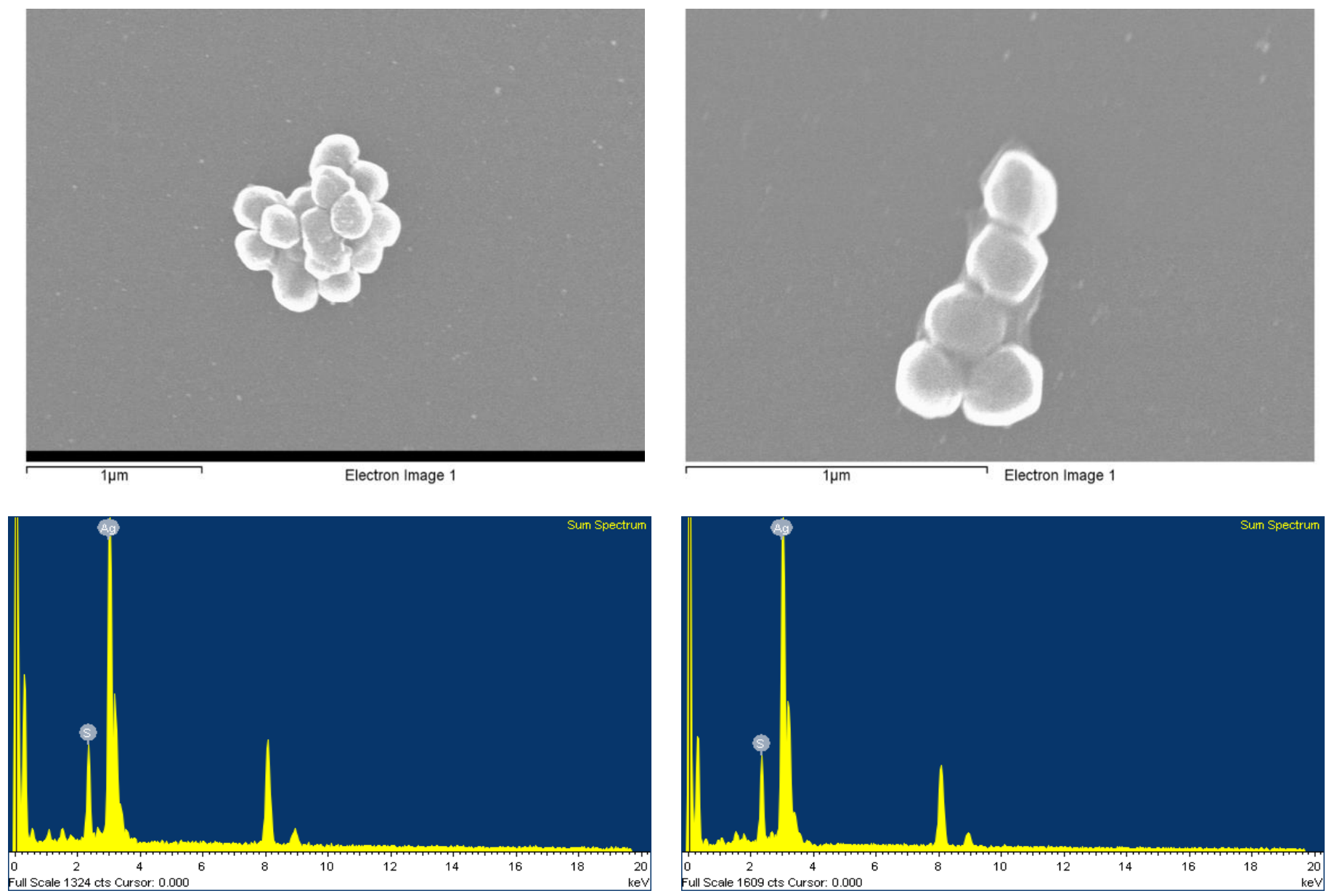

Figure S 13: EDS images and data of mid-point of sulfidation reaction of $\lambda 540$ particles 